\title{
Da imagem ao texto: A construção do tópico discursivo em manuscritos escolares de histórias em quadrinhos
}

Este trabalho é financiado pelo CNPq (processo 302130) e pela FAPEAL (processo 2002.09.003-03).

\section{DENNYs DIKSON}

Doutorando em Linguística pelo Programa de Pós-Graduação em Letras e Linguísticas da Universidade Federal de Alagoas.

Resumo: Inserido no campo de estudo da Genética Textual e assumindo como base teóricometodológica os estudos sobre manuscritos escolares e processos de escritura em ato de alunos recém-alfabetizados (CALIL, 2008, 2009), este trabalho analisa a construção do tópico discursivo (LINS, 2008) a partir da sequência de imagens oferecida por uma história em quadrinhos da Turma da Mônica. Nosso objeto de investigação é o manuscrito "O Cebolinha Atrapalhado", escrito por duas alunas do $2^{\circ}$ ano do Ensino Fundamental (08 anos de idade), no qual constatamos que o tópico discursivo construído pela interpretação das alunas é feito a partir do destaque de alguns elementos imagéticos relacionados à ação isolada do personagem e de cada quadrinho e não pela articulação narrativa entre eles.

Palavras-chave: processo de criação; tópico discursivo; relação imagem-texto; história em quadrinhos

\section{Eduardo CaliL}

Doutor em Linguística pela Unicamo, Professor dos Programas de Pós-Graduação em Letras e Linguísticas e de Educação da Universidade Federal de Alagoas. Pesquisador do CNPq.

Abstract: Inserted in the field of study of Textual Genetics and assuming as a basis theoreticalmethodological studies on school manuscripts of the processes and scripture in act of pupils newly-literate (CALIL, 2008, 2009), this work analyzes the construction of the topic discursive (LINS, 2008) from the sequence of images offered by a history in comics of Monica's Gang. Our object of research is the manuscript " $\mathrm{O}$ Cebolinha Atrapalhado", written by two pupils from $2^{\text {nd }}$ Grade (08 years old), in which we note that the topic discursive built by the interpretation of the pupils is done from the highlight of some elements of image isolated related to the action of the character and each comic and not by the articulation narrative between them.

Keywords: creation process; topical discursive; image-text relationship; comic strips 



\section{Algumas palavras}

O presente estudo situa-se na linha de investigação proposta por Calil $(2008,2009)$ ao analisar manuscritos escolares e processos de criação e escritura de diferentes gêneros textuais em contextos escolares, a partir da interação entre dois alunos recém-alfabetizados. O objeto de estudos envolvendo a análise deste material põe em relevo a escrita - em díades de alunos - de um único manuscrito escolar, cujo procedimento de coleta de dados é feito através da filmagem da interação desses discentes. ${ }^{1}$ Nosso olhar investigativo pretende pôr em relevo a construção do tópico discursivo (LINS, 2008) e a relação imagem-texto produzidas e colocadas no papel por duas alunas do Ensino Fundamental enquanto inventam uma história em quadrinhos. ${ }^{2} \mathrm{O}$ destaque para tais características impressas no manuscrito permitirá significativos avanços na compreensão do processo de criação deste gênero e no modo como a imagem interfere no texto escrito pelas discentes, sendo esse termo - "processo" - entendido a partir do que ele pode indiciar sobre a subjetividade do scriptor, aproximandose do sentido dado a dito termo pela Critica Genética (GRÉSILLON, 1994), ou seja, o processo é entendido enquanto um funcionamento de mão dupla, em que tanto o escrevente produz o texto, quanto o texto que está sendo escrito interfere nas "decisões" daquele que escreve.

É a partir desta consideração que o manuscrito escolar tem sido objeto de estudos valiosos para a compreensão dos meandros da criação de textos em sala de aula, como pode ser observado em Calil (2004) ao discutir o modo como a homonímia pode interferir na produção do manuscrito, em Calil e Lima (2007) e Calil (2010) ao darem destaque para a criação de nomes próprios e títulos de histórias inventadas, ou ainda em Santos e Calil (2010), quando são eleitos também manuscritos escolares de histórias em quadrinhos e a criação de onomatopéias.

Em nosso trabalho, o ponto de partida será a relação imagem-texto - inerente ao gênero $\mathrm{HQ}$ - e a

\author{
${ }^{1}$ É muito relevante \\ frisar que, embora seja \\ imprescindível explicar \\ o processo de escritura \\ em ato por ele fazer \\ parte integrante do \\ contexto metodológico \\ posto em prática, no \\ presente artigo, iremos \\ discutir especificamente \\ um manuscrito escolar \\ nascido de tal processo. \\ Este, por sua vez, será \\ analisado em outra \\ oportunidade.

\footnotetext{
${ }^{2}$ Doravante HQ [tanto para história em quadrinhos quanto histórias em quadrinhos].
} 
construção do tópico discursivo montadas pela díade quando produz a história. Tomando como objeto de investigação um manuscrito escolar, consideraremos o texto que acompanha cada quadrinho, procurando responder às questões: de que forma as alunas constroem - ou não -, em seu texto, o tópico discursivo? Como leem as imagens, seu encadeamento narrativo e o modo como "escrevem" esta interpretação?

\section{Pontos essenciais}

Além do papel da imprevisibilidade, do equívoco, que o processo de escritura em ato - expressão esta posta para designar o momento em que a dupla de crianças está escrevendo seu texto, na sala de aula, com todas as possibilidades pragmáticas de ocorrência, como, por exemplo, uma boa ou má interação da díade, com as concordâncias do que será escrito ou com as tensões que a produção pode aflorar nos alunos (CALIL, 2008) - mostra quando a díade está construindo um manuscrito, dois pontos teóricos são imprescindíveis na constituição desse gênero e no foco do olhar voltado a esse texto produzido pelas alunas: trata-se da relação imagem-texto e do tópico discursivo que, embora sejam aspectos indissolúveis para a formação do sentido narrativo constituinte das HQ explicitaremos, separadamente, suas sustentações com o fito de que fiquem mais bem compreendidos os objetivos que aqui serão trilhados.

\subsection{0 imprevisível no processo}

O trabalho sobre análise de manuscritos escolares, em especial dos que nascem do processo de escritura em ato, procura estabelecer, a partir de nosso ponto de vista teórico, as relações entre sujeito, língua e sentido. Essa busca faz o pesquisador desembocar, principalmente com a metodologia que aqui é posta em evidência, na imprevisibilidade-rasuras, equívocos-queocorredurante o escrever do texto dos alunos: algo que "aponta para a singularidade de um sujeito que escreve" (FELIPETO. 
2007, p. 100). E como essa cinesia do fazer texto é posta no papel a partir do que foi discutido e combinado pelas díades, o inesperado se manifesta não apenas no texto, mas, também (embora não seja nosso foco, é importante que fique frisado), no momento da coenunciação, e isso ocorre, por vezes, através do ato de rasuramento - oral e escrito -, sendo este entendido, conforme aponta Felipeto, como "a possibilidade de reformulação, daí ela [a rasura] ser fundamental no processo de produção textual em sala de aula ou fora dela." (2008, p. 13).

Essa compreensão de que o texto-fim das duplas nasce da produção escrita articulada com o oral, ambos dentro do não-previsível, é muito valiosa na investigação que estamos a propor - mesmo que a análise em tela recaia exclusivamente sobre o manuscrito -, pois é preciso compreender, nas relações ocorridas no processo de discussão imagem-texto, que a díade "procurando aproximar-se da forma certa, correta, (...) acaba por dizer/ escrever o 'errado', produzindo um erro ou um equívoco" (FELIPETO, 2008, p.13). Ou seja, o imprevisível aflora certo estranhamento, um "ponto de partida para que se produza um efeito de retorno, sem o qual não há rasura, naquilo que o equívoco já se fez presente ou poderá, a partir da rasura, se instalar" (CALIL \& FELIPETO, 2000, p. 3) - tendo-se, assim, um sujeito afetado, marcado, pelo seu falar no próprio escrito, ocorrendo, dessa feita, as reformulações.

\subsection{HQ: um gênero particular}

Sempre que o tema HQé cercado, a primeira ideia que normalmente surge são as sucessões das imagens [com personagens] e seus respectivos diálogos, formando uma sequência narrativa; e é nesse caminho que Vergueiro nos instrui, quando argumenta que "as histórias em quadrinhos constituem um sistema narrativo composto por dois códigos que atuam em constante interação: o visual e o verbal" (2004, p. 31). É essa constância da imagem com o verbal - ambos complementando-se 
mutuamente, ainda que haja HQ sem texto - uma das condições que dá estatuto ao gênero em questão.

Além disso, Ramos esclarece que os quadrinhos se apresentam "como se um determinado instante fosse congelado, por mais que, eventualmente, possa sugerir movimento", e acrescenta que neles "agrupam-se cenário, personagens, fragmentos do espaço e do tempo" (2009, p. 89); essa delimitação nos faz entender que a imagem mais precisamente a sequência de imagens ou, digamos, o congelamento agrupado - é o coração das $\mathrm{HQ}$ permitindonos afirmar que, embora algumas HQ sejam compostas apenas de imagens, o escrito, quando existe, precisa encontrar-se com o imagético de tal forma que o instante representado por cada um dos quadrinhos possa ser contextualizado pelo leitor e, ao mesmo tempo, a relação entre as imagens possa ser sustentada narrativamente. É a constância das imagens - acompanhada ou não de texto escrito - um forte aspecto pontual que permite à HQ se constituir enquanto um gênero bastante específico, como observa Vergueiro (2004, p. 35):

o quadrinho [...] constitui a representação, por meio de uma imagem fixa, de um instante específico ou de uma sequência interligada de instantes, que são essenciais para a compreensão de uma determinada ação ou acontecimento (grifo nosso).

Tais posições deixam evidente que a compreensão de HQ depende das articulações estabelecidas pela contiguidade imagética e narrativa. Porém, quando esse sequenciamento é acompanhado por textos, o leitor terá que estabelecer um fechamento ou encaixe de sentidos que possa ser construído nas relações com o visual. E uma das características principais desses textos que acompanham a sequencia de imagens é, em grande parte das $\mathrm{HQ}$ sua apresentação na forma de discurso reportado direto, o que traz à tona exatamente o diálogo entre os personagens representados nas imagens de cada 
quadrinho: no nosso caso em particular - as HQ da Turma da Mônica ${ }^{3}$ (doravante TM) - trata-se de narrativas que, na maioria das vezes, mantêm uma relação imagem-texto na forma de reportação direta.

\subsection{A sustentação tópica}

Do que foi colocado, é possível afirmar que a relação imagem-texto nas HQ ganha estabilidade através de um ininterrupto que se faz das figuras impressas nas sequências quadrinhais, adicionadas, quando há, à fala dos personagens participantes da história. Em outros termos: a progressividade lógica, a contiguidade narrativa ou, como defende Lins (2008), o "tópico discursivo" se constitui a partir deste continuum.

Tendo como ponto de princípio os estudos em linguística textual formulados por Koch et al. (1992), vêse duas propriedades que definem essa categoria "tópico": a de centração e a de organicidade. Lins (2008), também usando a mesma esteira desses autores, explica que, na propriedade de centração - que significa "falar-se de alguma coisa" (p. 15) -, há os traços de

1) Concernência: a relação de interdependência semântica entre os enunciados - implicativa, associativa, exemplificativa, ou de outra ordem - pela qual se dá sua integração no referido conjunto de referentes explícitos ou inferíveis; 2) Relevância: a proeminência desse conjunto, decorre da posição focal assumida pelos seus elementos; e 3) Pontualização: localização desse conjunto, tido como focal em determinado momento da mensagem. (p. 20-21)

Já na segunda propriedade - a organicidade prevalecem as relações de "interdependência estabelecidas simultaneamente nos planos hierárquico e sequencial" (p. 21), ou seja, a conjuração das imagens juntamente com os textos que carregam, necessitam apresentar-se em organização na linha discursiva dos tópicos em suas 
respectivas posições nas $\mathrm{HQ}$ com uma ordenação que garanta a união do que vem antes com o que vem depois [sequencialmente] e do que está acima ou detém mais importância com o que está abaixo ou não é tão relevante para a história [hierarquicamente], formando um tópico maior ou principal.

Assim, notamos que a manutenção do tópico discursivo exige o estabelecimento de uma amarra contínua da imagem-texto que garanta a harmonização da sequência narrativa que é constituída por "partes" ou quadrinhos individuais. Explicando melhor: o sentido que cada cena (quadrinho) das HQ exerce no conjunto narrativo é apreendido através da noção de subtópico, sendo este entendido "como uma sequência tópica relevante encaixada na sequência tópica principal. As sequências de subtópicos devem ser subordinadas às sequências tópicas principais..." (LINS, 2008, p. 22): é a união dos subtópicos discursivos nos posicionamentos quadrinhais que monta o sentido geral da narrativa, o tópico principal.

Dessa forma, apreendemos, da mesma maneira que Lins (2008) - quando parte dos trabalhos feitos por Goutsos (1996) - que o tópico, conjuntamente com a definição supramencionada, pode ser entendido teoricamente como uma estrutura que se opera organizadamente, e "não é definido e identificado como uma unidade a priori, mas como resultado de marcação de fronteiras" (p. 19): eis a consistência e relevância dos subtópicos delimitando a divisão dos sentidos colocados nos quadrinhos com o intuito de aflorar uma compreensão tópica maior e global. Isso permite a seguinte compreensão: o tópico é uma junção de outras várias fronteiras, de outros (sub-)tópicos, de açõesimagens agindo num constante vai-vem, articulando-se como um sistema interdependente para criar sentidos nas $\mathrm{HQ}$.

Apenas com o intuito de aparar as arestas - já que a proposta de produção sugerida às alunas, abaixo 
mostrada, em seu formato original, não apresenta fala entre os personagens Mônica e Cebolinha -, e reforçando os argumentos acima elencados, vemos que o sentido da história não cabe ao texto, mas às sequências contextuais imagéticas, o que significa dizer que o escrito, as falas, não são necessárias às HQ para que a narrativa ganhe molde. Nessa trilha, Ramos diz que "As expressões faciais e as metáforas visuais se somam aos gestos dos personagens e à postura do corpo", acrescentando que esse conjunto de aspectos se complementa "em perfeita sintonia com a imagem representada, de modo a reforçar o sentido pretendido" (2009, p. 114-115); o que nos leva a entender que a noção tópica geral não é definida apenas por marcas de enunciação, mas pela junção destas [caso exista] com todos os outros recursos permitidos nas imagens quadrinhais. Melhor dizendo: é a condição visual, com ou sem conversação, que permite as formações de um ou vários sentidos.

É importante ressaltar que a noção de tópico discursivo, tal qual aqui tomamos, é dada a partir da análise de HQ que circulam socialmente, gêneros estabelecidos e validados que são escritos por autores adultos e recebidos por leitores experientes. Certamente não consideramos que as alunas, ao escreverem o texto de uma $\mathrm{HQ}$ partiram das mesmas considerações tópicas que nós partiríamos. Nosso desafio está em analisar justamente como esta construção se dá.

\section{Um passeio no fazer manuscrito}

Dentro da perspectiva teórico-metodológica de caráter etnolinguístico, propomos discutir textos que ganharam origem no processo de criação em contexto escolar, isto é, manuscritos construídos a partir da interação entre díades de alunos quando conversavam, inventavam e escreviam juntos uma única HQ. Tais interações foram filmadas, e os registros destes processos envolveram o gênero escolar "histórias em quadrinhos" da TM e foram coletados durante o desenvolvimento do 
${ }^{4}$ Aproveitamos a oportunidade para agradecer à direção da escola, aos professores e alunos envolvidos, em particular, as duas alunas que participaram do processo de escritura em ato que analisaremos. A coleta de dados foi realizada durante os meses de outubro a dezembro de 2008. Este corpus pertence ao acervo Práticas de Textualização na Escola (PTE), sediado no Laboratório do Manuscrito Escolar (L'ÂME) - PPGE da Universidade Federal de Alagoas. Todos os participantes assinaram o termo de consentimento exigido pelo Comitê de Ética desta universidade.

${ }^{5}$ Famílias quase nãoletradas: dos pais das alunas que executaram a proposta em questão, um casal tinha o ensino fundamental completo, e o outro apenas até a $4^{\mathrm{a}}$ série do fundamental, sendo as mães "donas de casa" e os pais sem profissão definida, além de uma das famílias ser atendida pelo Programa Bolsa Família. projeto didático intitulado "Gibi na Sala", com alunos de um 2 o ano do Ensino Fundamental de uma escola da rede pública da cidade de Maceió. ${ }^{4}$

Partindo da concepção didática de que as condições de produção de um texto devem estar relacionadas à imersão dos alunos no gênero eleito, nossa proposta favoreceu a leitura de uma significativa quantidade de $\mathrm{HQ}$ da $\mathrm{TM}$, tendo sido constituído um corpus composto por um conjunto de 12 filmagens de processos de escritura em ato. Cada processo refere-se a uma produção manuscrita por cada dupla de alunos - lembrando que todos os discentes realizavam as atividades em duplas, sendo que apenas uma díade era filmada por aula -, e dentre tais manuscritos, elegemos um para análise, conforme adiante apresentado.

$\begin{array}{ccc}\begin{array}{c}\text { Mencionadas } \\ \text { quinzenalmente, }\end{array} & \begin{array}{c}\text { propostas, } \\ \text { apresentavam-se }\end{array} & \begin{array}{c}\text { realizadas } \\ \text { "semi- }\end{array}\end{array}$
estruturadas", isto é, continham as imagens organizadas sequencialmente, como no texto original, com exceção da parte escrita. Explicando com mais detalhes: oferecemos aos alunos pequenas HQ da TM, publicadas no Portal da Mônica e em gibis impressos, de uma ou duas páginas, as quais os discentes não tiveram acesso anteriormente. Apagamos digitalmente, com a ajuda do programa de computador PAINT, todas as referências lingüísticas destas HQ isto é, as falas dos personagens, títulos, interjeições, onomatopéia e, inclusive, as marcas tipográficas que indicam a fala, como por exemplo, os balões. Os alunos apoiavam-se somente na sequência de imagens, fotocopiadas em preto e branco, para inventarem o texto que julgassem necessário.

Este tipo de proposta se justifica por duas razões. A seleção das HQ da TM permitiria aos alunos pouco letrados ${ }^{5}$ acesso ao universo cultural proposto por este gênero. Em segundo lugar, acreditamos que a solicitação de se escrever uma HQ sem dar nenhum tipo de apoio visual, exigindo do aluno de apenas 8 anos a criação dos 
personagens, do "storyboard", das cores e traços, etc., seria uma proposta didaticamente inadequada.

Das 12 filmagens coletadas, selecionamos três em que participaram a mesma dupla - Ana e Maria, respectivamente com 8 anos e 1 mês e 8 anos e 2 meses de idade -, e para transcrição das filmagens, empregamos o programa ELAN ${ }^{6}$ por permitir a sincronização entre a imagem captada e o áudio registrado. Não discutiremos, aqui, essas filmagens e suas transcrições, pois, nosso olhar, vai recair exclusivamente sobre o manuscrito que foi produzido na 2 a filmagem feita em sala de aula, mas a 1 a em que Ana e Maria trabalharam juntas. É importante ressaltar que estas mesmas alunas atuaram juntas em outros dois momentos, quais sejam, em 16/10/2008 e em 30/10/2008, e produziram, respectivamente, os manuscritos "O Meu Cachorro Dorminhoco" e "O Passeio com Cebolinha e a Mariazinha”. ${ }^{7}$

O foco de nossas análises recairá no texto intitulado "O Cebolinha Trapalhado" e construído no dia 08 de outubro de 2008, aula em que o professor leu com a turma alguns quadrinhos de outra história da TM, discutindo certas características das HQ como a fala dos personagens, o balão para marcar o diálogo, a sequência imagética e as pistas que as imagens dão para produção do texto escrito, dentre outras. Logo em seguida, foi entregue aos alunos, já organizados em díades, a proposta de produção com uma HQ de duas páginas. ${ }^{8}$ As díades deveriam combinar, inventar e escrever o que julgassem necessário, tendo como ponto de partida: ${ }^{9}$

\section{${ }^{6}$ Eudico Linguistic Annotator; programa desenvolvido pelo Max Planck Institute for Psycholinguistics e pode ser obtido gratuitamente em www.lat-mpi.eu.}

${ }^{7}$ Ambos os manuscritos, juntamente com suas filmagens e transcrições, são objetos de análise no projeto de mestrado do 1 o autor deste artigo, que está em andamento e com previsão de defesa para o trimestre 2011.4.

${ }^{8} \mathrm{Na}$ primeira página: do 1o ao $4^{\circ} \mathrm{Q}$ e na segunda: do $5^{\circ}$ ao $11^{\circ} \mathrm{Q}$.

\footnotetext{
${ }^{9}$ A proposta foi retirada no sítio www.monica. com.br (página semanal 01); os quadrinhos serão numerados para os fins deste artigo $\left(1{ }^{\circ} \mathrm{Q}\right.$ : primeiro quadrinho; 2Q: segundo quadrinho, ...).
} 

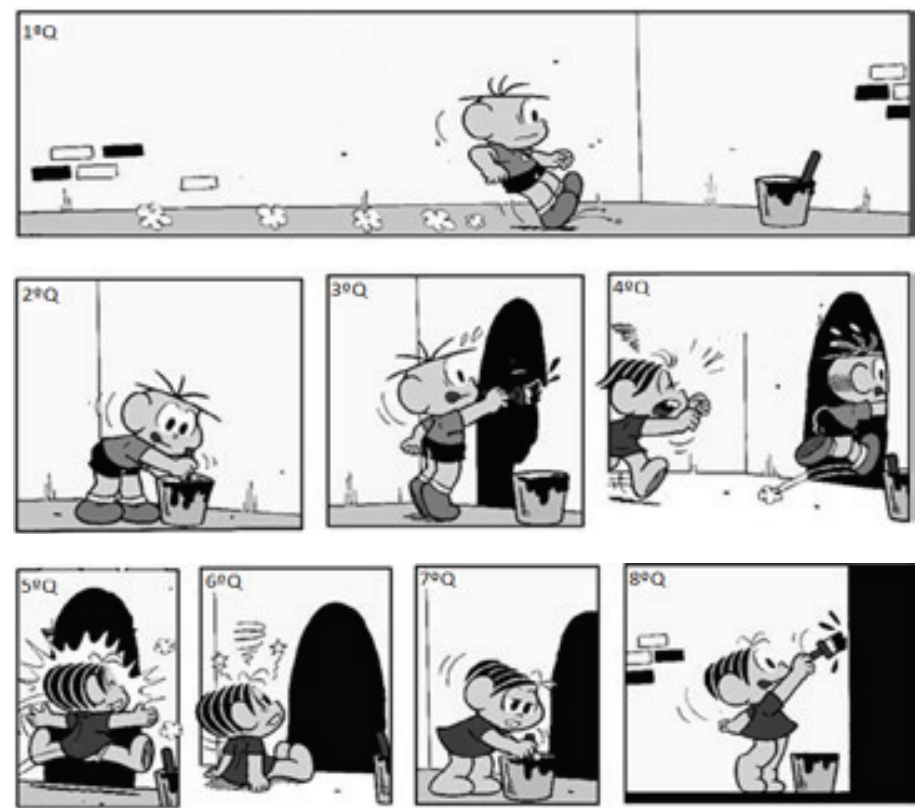

${ }^{10}$ Outra forma de se referir à Turma da Mônica.

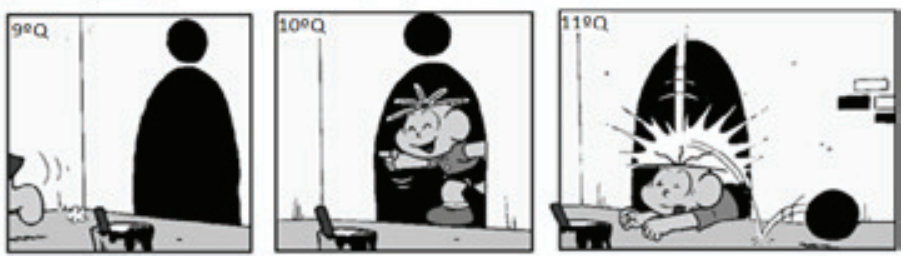

\section{A proposta dada e o tópico discursivo possível}

Se observarmos a sequência de imagens desta HQ o tópico discursivo central - para o leitor letrado - está relacionado às ações dos personagens Cebolinha e Mônica e aos elementos imagéticos presentes na cena narrativa ("fumacinhas" indicando Cebolinha em correria, "balde" ou "lata" de tinta preta com "pincel", "parede de tijolos", entrada de um "túnel” ou "passagem", "bola pesada" caindo). Cada personagem usa-os a partir de seu ponto de vista: o Cebolinha para "fugir" da Mônica, a Mônica para "bater" no Cebolinha, trama clássica das HQ da TM. Para o leitor dos gibis da turminha ${ }^{10}$, conhecedor das relações de disputa e provocação entre estes dois personagens (ex.: plano infalível para derrotar 
a Monica; amarrar as orelhas do seu coelhinho Sansão; bater nos meninos, geralmente o Cascão e o Cebolinha, com o Sansão; xingá-la de "gorducha" e "dentucha", etc.) e do universo discursivo destas $\mathrm{HQ}$ este tópico pode ser construído com certa facilidade, ainda que não haja textos acompanhando os quadrinhos.

Para tal entendimento, é essencial compreender o continuum que amarra as cenas dessa $\mathrm{HQ}$ ou seja, a costura das ações carece dar força de contiguidade à história para a formação tópica ter sentido. A centração precisa ser notada de forma consistente; explicando melhor: sua estruturação - a concernência dos quadrinhos, com a interdependência da conjuntura explícita ou inferível, face não haver diálogos; a relevância assegurando a saliência do conjunto dos quadros, a partir dos elementos imagéticos que assumem determinadas posições focais de ações; e a pontualidade que demonstra cada ato, cada foco, cada ação, nos quadrinhos individualmente -, juntamente com organicidade hierárquica e sequencial imagética [ordenação e relevância de posicionamento], são o que fazem produzir tal contínuo, assegurando ao leitor assimilar os acontecimentos por cena e, consequentemente, fixar um tópico discursivo central.

É interessante notar que na HQ original, os quadrinhos em tela não apresentam diálogo, somente onomatopeias. ${ }^{11} \mathrm{O}$ que ergue o tópico discursivo principal são as ações, gestos dos personagens, seus posicionamentos, bem como imagens e metáforas visuais. ${ }^{12}$ É importante que isso fique frisado, pois, como vai ser observado, não podemos fazer comparações exatas entre o que o autor pôs na HQ com o que a dupla escreveu, posto que na proposta foi solicitada exatamente que fosse inventada a história a partir do imagético, nada foi pedido ou trabalhado em sala no que tange à produção da narrativa sem o escrito.
${ }^{11}$ Não apresentaremos a HQ original não apenas por conta do limite de espaço imposto a este artigo, mas também porque ele não é relevante para a análise que desenvolveremos a seguir.

\footnotetext{
12 Temos metáfora visual como "uma forma de expressar idéias ou sentimentos por meio de imagens" (RAMOS. 2009, p. 112).
} 


\section{O manuscrito e o tópico: algumas reflexões}

Ao observarmos o manuscrito das alunas ${ }^{13}$,

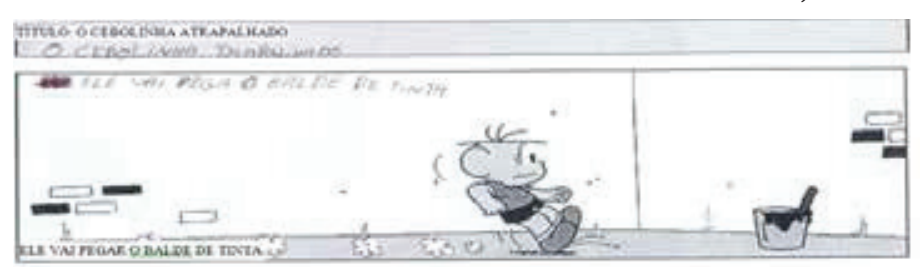

${ }^{13} \mathrm{O}$ manuscrito está apresentado com as respectivas legendas de cada quadrinho e escrito com as devidas correções ortográficas, entretanto, logo abaixo, colocamos a transcrição da forma como as alunas escreveram.
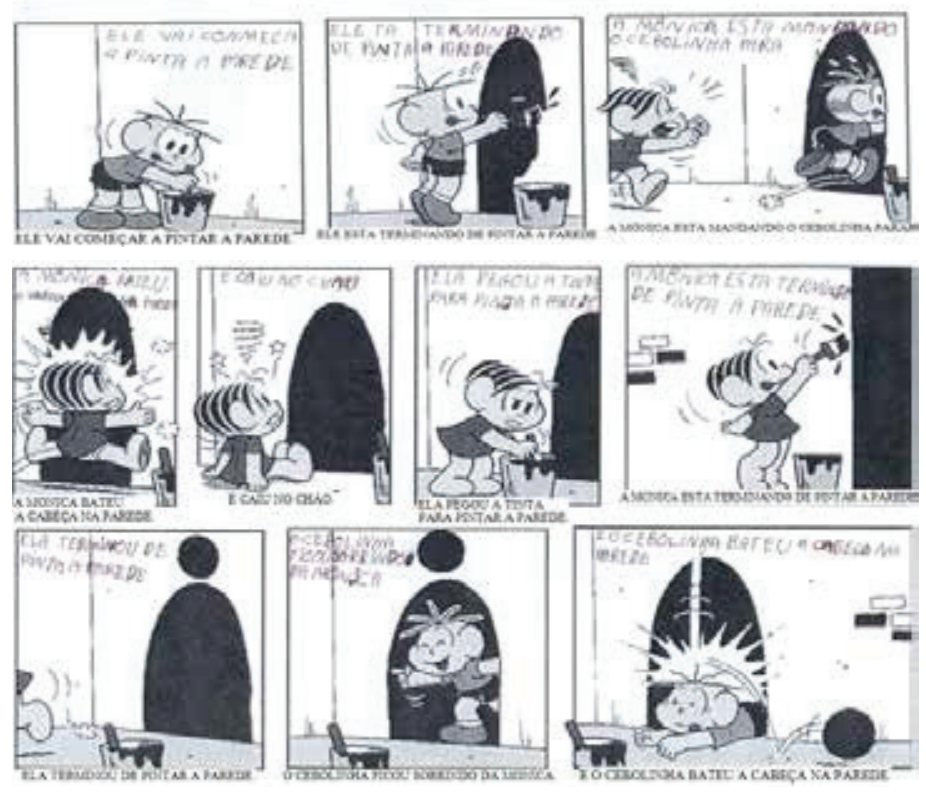

encontramos o seguinte texto por elas escrito, correspondente a cada quadrinho:

Título: O CEBOLINHA TRAPALHADO

1Q: ELE VAI PEGA O BALDE DE TINTA.

2 Q: ELE VAI COMEÇA A PINTA A PAREDE.

3o Q: ELE TA TERMINANDO DE PINTA A PAREDE.

4ㅇ: A MÔNICA ESTA MANDANDO O CEBOLINHA PARA.

5 Q: A MÔNICA BATEU A CABEÇA NA PAREDE.

6o Q: E CAIU NO CHÃO.

7ㅇ: ELA PEGOU A TINTA PARA PINTA A PAREDE.

8ㅇ: A MÔNICA ESTA TERMINANDO DE PINTA A PAREDE. 
9o Q: ELA TERMINOU DE PINTA A PAREDE.

10ㅇ: O CEBOLINHA FICOU SORRINDO DA MÔNICA.

11Q: E O CEBOLINHA BATEU A CABEÇA NA PAREDE.

Comparando o que escreveram as alunas no manuscrito escolar com a sequência de imagens da proposta mais acima mostrada, podemos observar significativas discordâncias com o tópico discursivo central anteriormente tecido. Desde o título (O CEBOLINHA TRAPALHADO) até o que escreveram no quadrinho final (E O CEBOLINHA BATEU A CABEÇA NA PAREDE), o texto escrito não se aproxima do tópico principal que descrevemos; o conflito entre os personagens e o elemento lúdico, componentes principais das HQ da TM, não é construído. Nesta HQ, Cebolinha e Mônica, ao lançarem mão dos elementos "balde", "tinta", "pincel", "parede" presentes na cena narrativa, constrói-os "a seu favor", isto é, o primeiro para "escapar" da segunda, e esta para "bater" naquele. A díade ainda escreve o texto sem apresentar qualquer forma de discurso reportado direto ou onomatopéia, elementos igualmente centrais deste gênero. Os enunciados que encontramos em todos os quadrinhos trazem uma estrutura típica de certa forma composta por descrição de imagens, sem uma consistente articulação narrativa entre si: cada um ou dois quadrinhos é descrito isoladamente, e a partir de um único ponto de vista, sem que se estabeleça um conflito claro entre os personagens.

Logo nos $1^{\circ}$ e $2^{\circ} \mathrm{Q}$ começamos a notar o escape da díade no que concerne à mantença tópica - o texto escrito no $1^{\circ} \mathrm{Q}$ só faz relação a partir do $2^{\circ} \mathrm{Q}$ e o que neste foi escrito, só a partir do 3Qㅜ ou seja, as alunas antecipam as ações do Cebolinha antes de efetivamente ocorrem. Vejamos: no 1Q (ELE VAI PEGA O BALDE DE TINTA) nada na imagem transparece que o personagem vai tomar o objeto, nem sequer se pode dizer se este objeto tratase precisamente de um "balde de tinta", mesmo assim as 
alunas precedem o que só podemos observar nas próximas cenas ( 2 e $3 \circ \mathrm{Q})$ quando realmente Cebolinha mexe a tinta preta e pinta a parede; no $2 \circ \mathrm{Q}$ (ELE VAI COMEÇA A PINTA A PAREDE) ocorre de forma semelhante, pois ainda não é possível afirmar, ao se considerar somente o quadrinho sem suas relações com os seguintes, que o balde contém tinta nem que haverá a ação de pintar a parede mostrada somente no $3 \circ \mathrm{Q}$. No texto que aparece neste (ELE TA TERMINANDO DE PINTA A PAREDE) há uma continuidade da ação de pintar, mas não do conflito narrativo que ainda não apareceu. Isso significa dizer que não só o tópico geral não foi construído por falta de concernência, mas os subtópicos, que funcionam como encaixes dentro do principal, também encontram-se numa posição de isolamento, visto que a relação imagemtexto estabelecida pela dupla até este momento tem como ponto central o personagem Cebolinha, sua ação de pegar o balde de tinta e pintar a parede.

Do 4o ao 9Q o tópico - ainda descritivo - é alterado para a personagem Mônica, elemento visual em destaque em todos estes quadrinhos. No 4 (A MÔNICA ESTA MANDANDO O CEBOLINHA PARA) há um, digamos, princípio de conflito narrativo, com a presença de um verbo sentiendi que reporta a uma fala indireta ("mandar parar"), mas que não tem continuidade nos quadrinhos posteriores. Do 5o ao 9o temos três ações: nas duas primeiras a Monica "bate a cabeça" e "cai no chão", mantém entre si uma relação de causa e efeito; a terceira ação que acompanha os 7o, 8 e 9o quadrinhos, está focado em "pintar a parede", sendo os objetos "tinta" e "parede" os elementos com relevância e pontualização para a díade.

Nos dois últimos quadrinhos (10ㅇ e 11) lê-se, respectivamente, "O CEBOLINHA FICOU SORRINDO DA MÔNICA" e "E O CEBOLINHA BATEU A CABEÇA NA PAREDE”. Novamente a leitura da imagem feita pela díade volta-se para o personagem Cebolinha, centralizado em cada um destes dois quadrinhos. Porém, enquanto no $10^{\circ} \mathrm{Q}$ o texto traz outro verbo sentiendi ("sorrir"), 
sugerido sobretudo pela expressão facial do personagem, o último quadrinho não expressa exatamente o que a cena indica (movimento da bola caindo sobre a cabeça dele e rolando para o lado, ele caído no chão com a língua de fora e os olhos fechados, cuja expressão indica dor). Elas desconsideram isso e repetem praticamente o mesmo enunciado $5^{\circ} \mathrm{Q}$ (A MÔNICA BATEU A CABEÇA NA PAREDE).

Destas observações podemos concluir que, do ponto de vista narrativo, os enunciados escritos não se encaixam uns aos outros, impedindo o engendramento do tópico principal. As alunas constroem relações imagem-texto pontuais e descritivas, elegendo os objetos "balde", "parede" e "tinta" (que emergem nos enunciados de 8 dos 11 quadrinhos) e a ação de "pintar", presente em 5 quadrinhos. Os traços de concernência - relações de interdependência semântica entre os enunciados -, de relevância e pontualização, cuja posição focal recai sobre o conjunto de objetos e ações, são desarticulados do ponto de vista enunciativo de cada personagem e da trama narrativa implícita nas ações de correr, fugir, pintar, bater.

Por fim, poderíamos dizer que as alunas constroem um tópico discursivo preso ao que "veem" nas imagens e não ao que se refere às características de cada personagem e ao pressuposto que sua sequência implica.

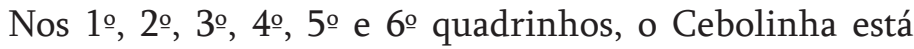
fugindo da Monica porque "aprontou" algo com ela, e, quando encontra o balde de tinta e a parede de tijolos, faz o desenho de uma entrada de túnel para se esconder, mas a entrada não "funciona" para Monica, que se choca na parede e cai no chão; isso mostra que a dupla fixa em formular uma narrativa de acordo com o "ato-ação" e a forma de pensar a história exclusivos do Cebolinha. Do 7o em diante, o texto produzido na HQ se inverte, passando esta a ser "narrada" do ponto de vista da Monica, que também usa o balde de tinta, faz uma bola preta pesada acima da entrada do túnel e, quando o Cebolinha sai para 
"caçoar" dela, a bola cai em sua cabeça, derrubando-o. O lúdico está no fato do "feitiço ter virado contra o feiticeiro", por assim dizer.

Em outras palavras, a nossa hipótese diz respeito ao fato de que a construção do tópico discursivo adequado para sequência de imagens proposta por esta HQ dependeria tanto das possibilidades lingüístico-cognitivas do scriptor mudar de perspectiva enunciativo-narrativa (ora da perspectiva do Cebolinha, ora da Mônica), quanto do modo como as propriedades lingüístico-discursivas do gênero em questão são significadas para as alunas. Esta dificuldade talvez esteja relacionada ao fato de elas não serem leitoras do gênero e, menos ainda, produtoras de HQ.

\section{Singelas considerações finais}

Ao contrário do que ocorrem com os contos de fadas, fábulas ou poesias, os manuscritos vindos dos processos de criação e escritura de $\mathrm{HQ}$ em contexto escolar são ainda objetos de estudo pouco investigados. Trilhar caminhos com o fito de tentar compreender de que modo alunos recém alfabetizados interpretam as imagens e se apropriam das características deste gênero poderá trazer significativas contribuições para o campo de estudo da Genética Textual, além do que abre outras brechas e possibilidades para se compreender as relações sujeito, língua e sentido a partir da análise de escrituras em ato.

A análise do manuscrito "O Cebolinha Trapalhado" indicou que a construção do tópico discursivo na criação do texto para a sequência de imagens da HQ exigiria uma tripla articulação da dupla:

a) articulação imagem-texto com o que está representado cada quadrinho;

b) articulação imagem-texto entre o que foi escrito em um quadrinho, em outro, em outro...; e 
c) articulação entre as perspectivas enunciativas dos personagens, seus "pontos de vista", levando em consideração os elementos centrais de cada cena representada.

A esta tripla articulação, podemos acrescentar que a construção escrita do texto - no caso da HQ seria o diálogo, quando o scriptor precisaria reportar na forma direta o ponto de vista do personagem, sem passar pelo discurso indireto próprio das narrativas ficcionais que não são sustentadas por uma sequência de imagens - é um elemento a mais que pode estar interferindo na manutenção do tópico discursivo; e essas são pistas que nos fazem buscar algumas repostas não tão simples e evidentes quando o assunto é a produção textual em dupla na sala de aula, mas que serão perseguidas na continuidade dos nossos estudos e que, talvez, o processo de escritura em si possa nos explicar, em outra oportunidade. 


\section{Referências}

CALIL, Eduardo. A escuta e o funcionamento da rasura. Revista Leitura (Maceió), v.20, 1997.

"Um manuscrito escolar e a interferência da homonímia no processo de escritura". Revista do Gelne, volume 6, no 2, João Pessoa: Idéia. (pg. 61 - 72) ISBN: 15177874, 2004.

Escutar o invisível: escritura \& poesia na sala de aula. São Paulo: Unesp, 2008.

Autoria: a aluna e a escrita de histórias inventadas.

2. Ed. Londrina: Eduel, 2009.

CALIL, Eduardo; FELIPETO, Sonia C. Sobre os mecanismos lingüísticos subjacentes ao gesto de rasurar. In. Gelne. 2000.

CALIL, Eduardo; LIMA, Maria Hozanete A. de.

"Nomes próprios em histórias inventadas: odores de um encadeamento". In: CALIL, Eduardo (org.). Trilhas da Escrita: Autoria, leitura e ensino. São Paulo : Cortez, 2007.

FELIPETO. Cristina. "Erro imprevisível: possibilidade esquecida da língua". In: CALIL, Eduardo (org.). Trilhas da Escrita: Autoria, leitura e ensino. São Paulo: Cortez, 2007.

FELIPETO, C. Rasura e equívoco: no processo de escritura em sala de aula. Londrina: Eduel, 2008.

GRÉSILLON, Almuth. Eléments de critique génétique: lire les manuscrits modernes. Paris: Presses Universitaires de France (PUF), 1994.

GOUTSOS, Dionysis. Modeling Discours Topic: Sequential Relations and Strategies in Expository Text. Norwood, New Jersey. Ablex Publishing Corporation. 1996. 
KOCH, I. G. V. et. Al. "Organização tópica da conversação". In: ILARI, Rodolfo (org). Gramática do português falado. São Paulo:Campinas, ed. da UNICAMP, 1992. V.3. 1996, pp. 357397.

SANTOS, Janaina. P. L. S; CALIL, Eduardo. "Como representar onomatopéias? Um estudo em manuscritos escolares de histórias em quadrinhos escritas por alunos do $2^{\circ}$ ano do ensino fundamental". Revista Leitura: Teoria e Prática, ano 27, número 54, Campinas, SP. 2010.

LINS, Maria da Penha Pereira. O tópico discursivo em textos de quadrinhos. Vitória: Edufes, 2008.

RAMOS, Paulo. A leitura dos quadrinhos. São Paulo:

Contexto, 2009.

VERGUEIRO, Waldomiro. "A linguagem dos quadrinhos: uma 'alfabetização' necessária”. In: RAMA, Ângela; WERGUEIRO, Valdomiro (org). 3. Ed. Como usar as histórias em quadrinhos na sala de aula. São Paulo: Contexto, 2006. PP. 31-64. 